\title{
DYNAMIC STABILITY ANALYSIS OF BEAM STRING STRUCTURES UNDER EARTHQUAKE LOADS
}

\author{
Qinghua Han ${ }^{1,}{ }^{*}$, Chenyin Ma ${ }^{1}$, Jingyu Zhang ${ }^{2}$ \\ ${ }^{1}$ Department of Civil Engineering, Tianjin University, Tianjin, 300072, China \\ ${ }^{2}$ Department of Mechanical Engineering, Tianjin University of Technology, Tianjin, 300191, China \\ *(Corresponding author: Email: qhhan@tju.edu.cn)
}

Received: 1 July 2005; Revised: 10 April 2007; Accepted: 18 April 2007

\begin{abstract}
Beam String Structure (BSS) is composed of an upper structural member, lower strings and struts, which is a new type of long-span hybrid structure. The study on the static behavior is extensive. However, there is still a certain extent of blank in the field of dynamics, especially the dynamic stability. Owing to the limitation of the existing dynamic stability judgment criterion, most of which are based on Lyapunov dynamic stability theory and the highly nonlinear earthquake response of BSS, the nonlinear finite element analysis and time history method (THD) are adopted. THD is effective to the highly nonlinear structures. Based on the displacement time history curves and structural deformation, the critical load of dynamic stability was obtained. The dynamic stability of the plane BSS is analyzed under earthquake loads in respect of the number of struts, height-span ratio, sag-span ratio, moment of inertia, prestressing force of string and restraint type of supports. The results are compared with those of static stability. Some suggestions are put forward to selecting a proper structural model and analysis in project design.
\end{abstract}

Keywords: Beam string structure; dynamic stability; earthquake loads; non-linear earthquake response; time history method; cable

\section{INTRODUCTION}

Beam String Structure [1] (BSS) is a new type of space structure, which is composed of an upper structural member, lower steel cables and struts. As shown in Figure 1, the upper structural member may be a beam, an arch, a plane truss or a solid truss and so on [2]. Applying pretension force to lower steel cables [3] causes the structure to deform to an inverted arch, which decreases the deflection of the structuresignificantly. On the other hand, horizontal thrust of the arch springing is offset by steel cables; consequently, both the stress dominance of the arched-type structure and the high tensile performance of the cables are displayed sufficiently. In the past decades, this type of Beam String Structure was accepted extensively all over the world [4]. For example, the steel box beam added with lower cables, a type of BSS, was adopted for the Basketball Arena of Badalona which was built for the Barcelona Olympic Games in 1992. In China, another type of BSS, the internal structure of solid cable-truss of the Guangzhou International Convention and Exhibition Center (GICEC) is shown in Figure 2, the structural span of which is $126.6 \mathrm{~m}$. The study on static behavior and the analysis of BSS are extensive [5-9]. However, as a new type of space structure, the domestic and overseas studies in the problem of dynamic stability of BSS are still in the initial stage.

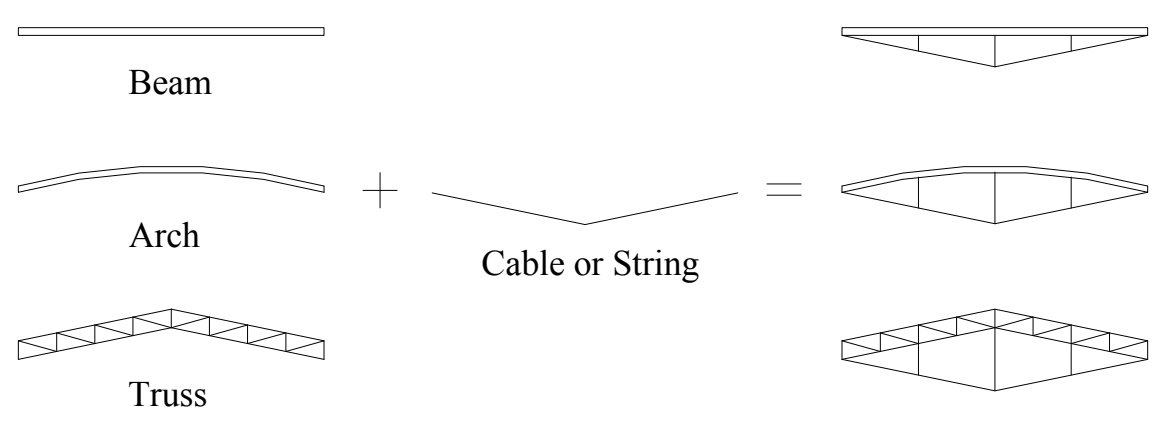

Figure 1. Forming Sketch of BSS 


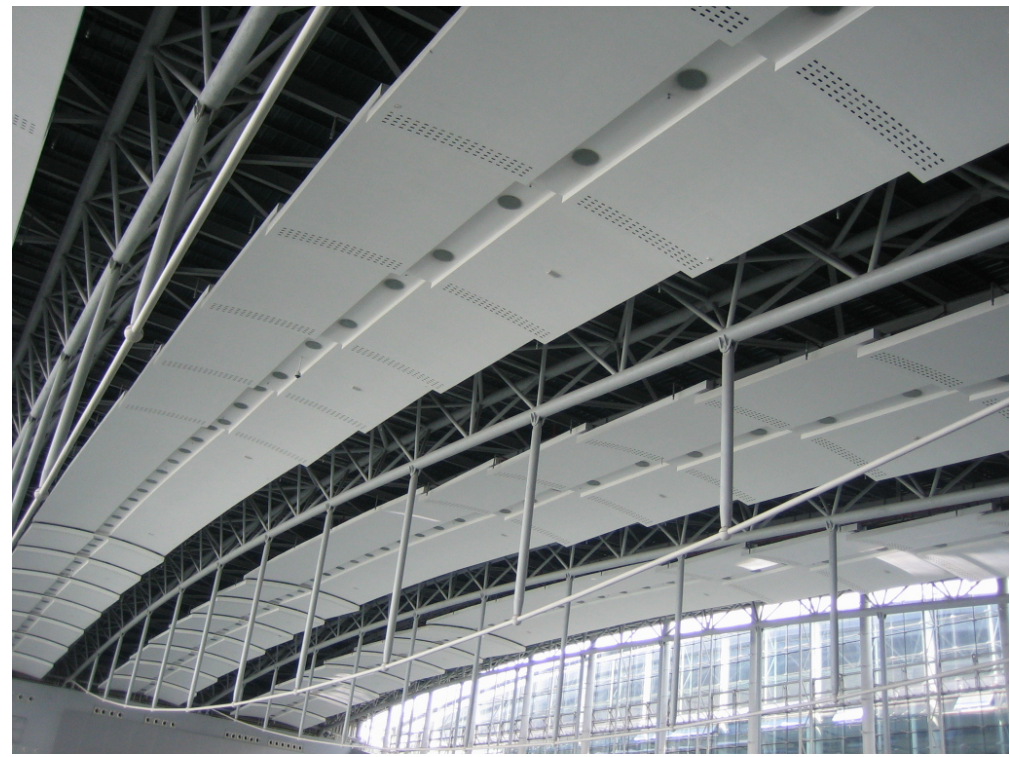

Figure 2. Structure of solid cable-truss of GICEC

This structure is of high nonlinearity. Based on well-established mathematical definition, the Lyapunov dynamic stability theory, in essence, is the study of the effect of the initial condition on the general equation of motion [10]. In other words, we adopted the definition that the structure subjected to a certain input is stable if small increases in the magnitude of excitation result in the small changes in the response [11,12]. The load that causes the loss of stability is identified as the critical load. In consideration of the high nonlinearity of dynamic stability and the multiple-degree-of-freedom system under time-varying loads, the effective dynamic stability judgment criterion is not available at present. This situation is a result of both the complexity of problem itself and the limitation of the Lyapunov theory. The dynamic stability analysis is predominant for some specific structures, which are initially studied in these references [13-18]. In some structures, there may be multiple equilibrium positions, the structure could swap among these positions under dynamic loads. Local dynamic buckling may occur in the structure under certain dynamic loads; however, after reaching new equilibrium position, the structure can still carry load or it may lose the entire dynamic stability. For this reason, the definition of dynamic stability based on mathematical definition is not indiscriminately imitated. Therefore, time history method is visualized and effective.

In this paper, nonlinear finite element method is used to study the dynamic stability of planar Beam String Structures under earthquake loads in respect of the number of struts, height-span ratio, sag-span ratio, moment of inertia, prestressing force of string and restraint type of supports.

\section{ANALYSIS METHOD}

This Beam String Structure, a type of hybrid structure, is composed of an upper arch, lower cables and struts. When analyzing the stability, upper chords are regarded as discrete plane straight beam elements, lower cables are treated as plane drag link elements which do not have the capacity to carry compression force, and struts are identified as plane links. Iterative algorithm is utilized in the geometric nonlinear finite element analysis. 


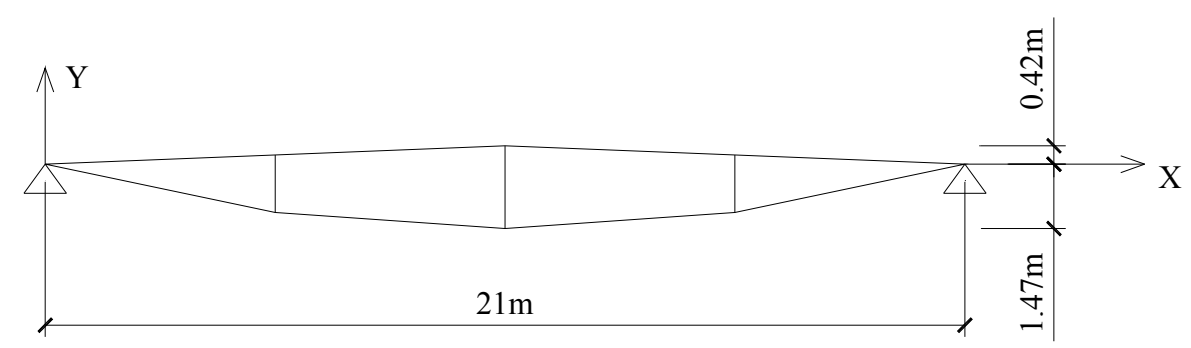

Figure 3. Elementary Model

Elementary model is single Beam String Structure, whose span is $21 \mathrm{~m}$, height-span ratio is 0.02 and sag-span ratio is 0.07. Its model is shown in Figure 3. The sectional dimension of upper beam and struts are $\Phi 259 \times 12$ and $\Phi 140 \times 10$ respectively. And lower cables used seven steel wires with a diameter of $5 \mathrm{~mm}$ (7Ф5). Fixed hinged supports are accepted. In addition, the prestressing force of the lower strings is $20 \mathrm{kN}$. The current general finite element analysis software ANSYS is applied to the time history method under earthquake loads. Upper chords, lower cables and struts employ BEAM3, LINK10 and LINK1 element respectively. During the process of calculation and analysis, large-deflection effects and damping are included. The damping ratio is 0.02 .

Firstly, the characteristics of self-excited oscillation of the structure is studied, which is calculated using modal analysis. Natural vibration frequency of elementary model is shown in the Table 1 . And Figure 4 illustrated the first eight modes.

Table 1. Natural Vibration Frequency

\begin{tabular}{|c|c|c|c|c|c|c|c|c|}
\hline Modal exponent number & 1 & 2 & 3 & 4 & 5 & 6 & 7 & 8 \\
\hline $\begin{array}{c}\text { Natural vibration frequency } \\
/ \mathbf{H z}\end{array}$ & 3.1 & 4.4 & 10.6 & 20.2 & 23.0 & 31.2 & 47.5 & 49.5 \\
\hline
\end{tabular}

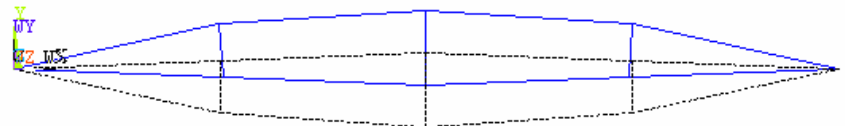

Mode 1

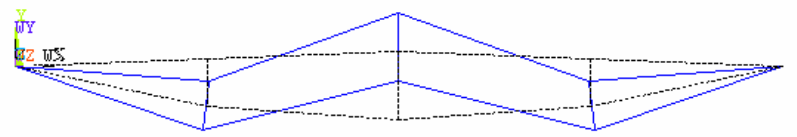

Mode 3

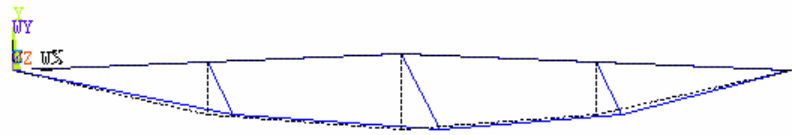

Mode 5

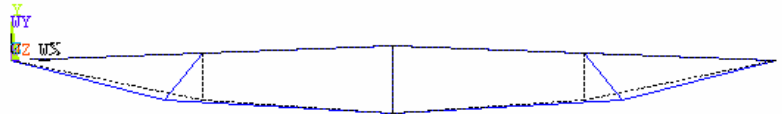

Mode 7

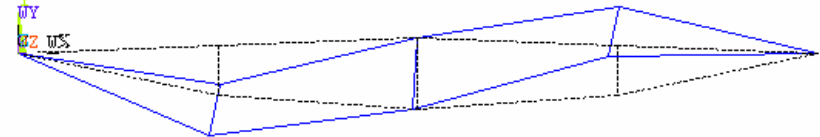

Mode 2

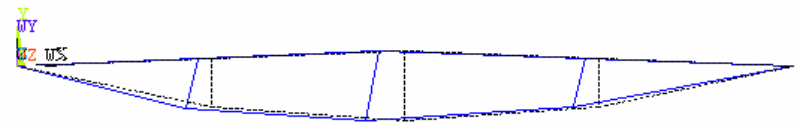

Mode 4

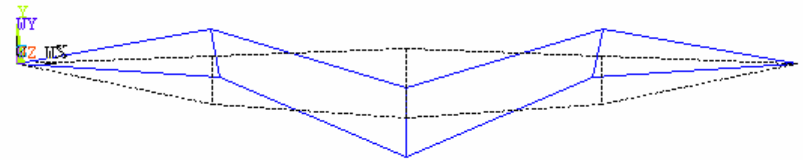

Mode 6

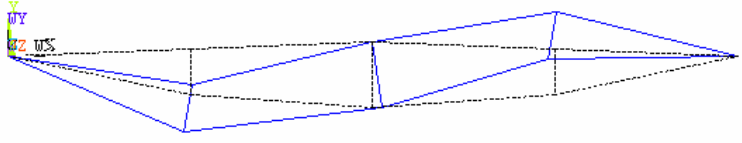

Mode 8

Figure 4. Mode Shape 
When it comes to the research of the earthquake response of this structure, loads by way of acceleration are applied, and the earthquake wave El-Centro spectrum is preferred. Its recording time-interval is $0.02 \mathrm{~s}$, and its duration is compressed to $8 \mathrm{~s}$ in the y direction, which is the direction of vertical earthquake loads.

According to former studies, it is proposed that if small load increment results in great changes in the characteristic response parameter, the situation can be regarded as dynamic instability, and this corresponding load is defined as the critical load of structural dynamic stability. Based on dynamic response of BBS, the node possesses the maximum structural displacement under seismic loads is specified as the structural characteristic response parameter.

Therefore, the time history curve of midspan nodal displacement response under the acceleration peak value of $341.7 \mathrm{gal}\left(1 \mathrm{gal}=0.01 \mathrm{~m} / \mathrm{s}^{2}\right)$ is shown in Figure 5 and Figure 6 . The response of midspan upper chord nodal vertical displacement is shown in Figure 7. It is indicated that the response of the nodal vertical displacement remains stable under the acceleration peak value that lies between 200gal to 1400gal. The dynamic characteristics of the structure does not change obviously. When reaching the acceleration of 1400gal, the nodal vertical displacement increases significantly and drives to damage. At this instance, it is shown that the dynamic stability critical load of this structure is between 1200gal and 1400gal.

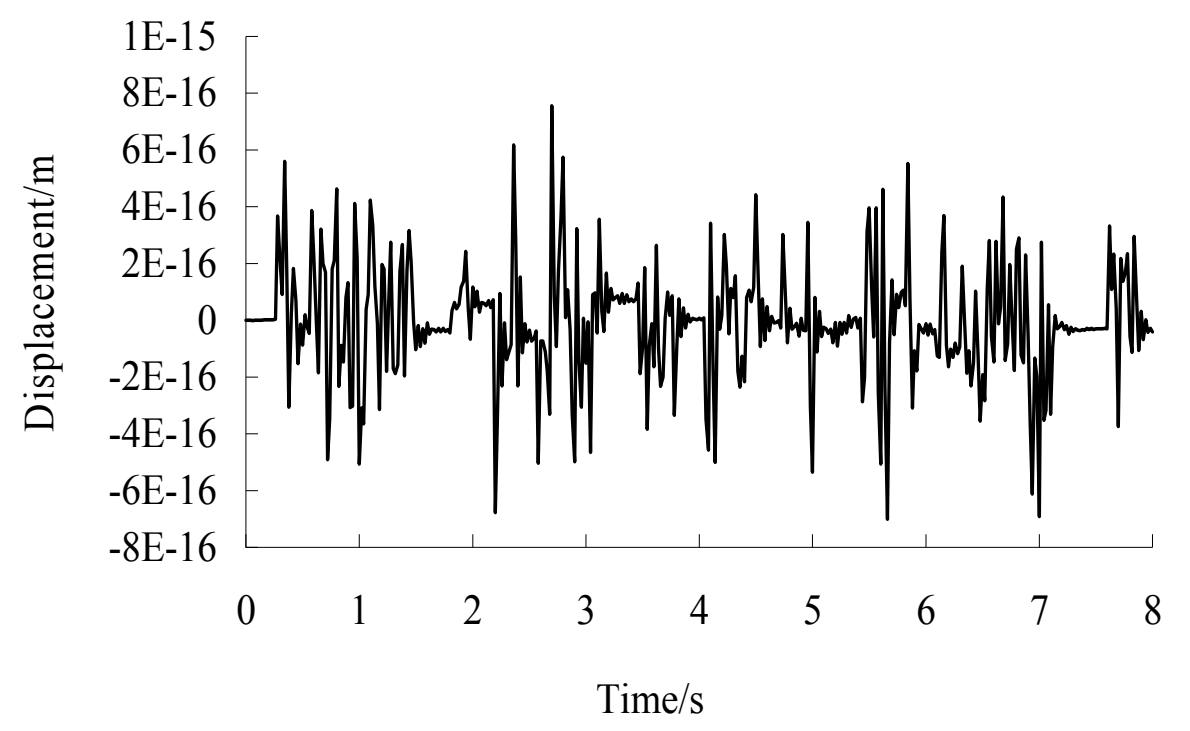

Figure 5. Time History Curve of Midspan Nodal Displacement in x Direction

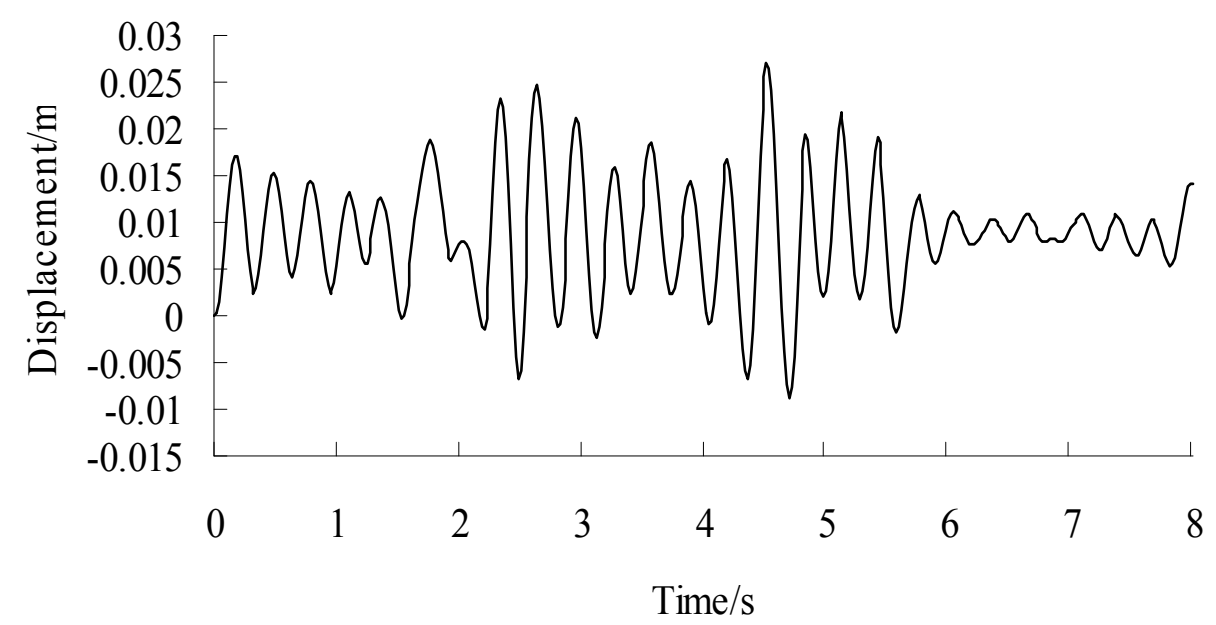

Figure 6. Time History Curve of Midspan Nodal Displacement in y Direction 


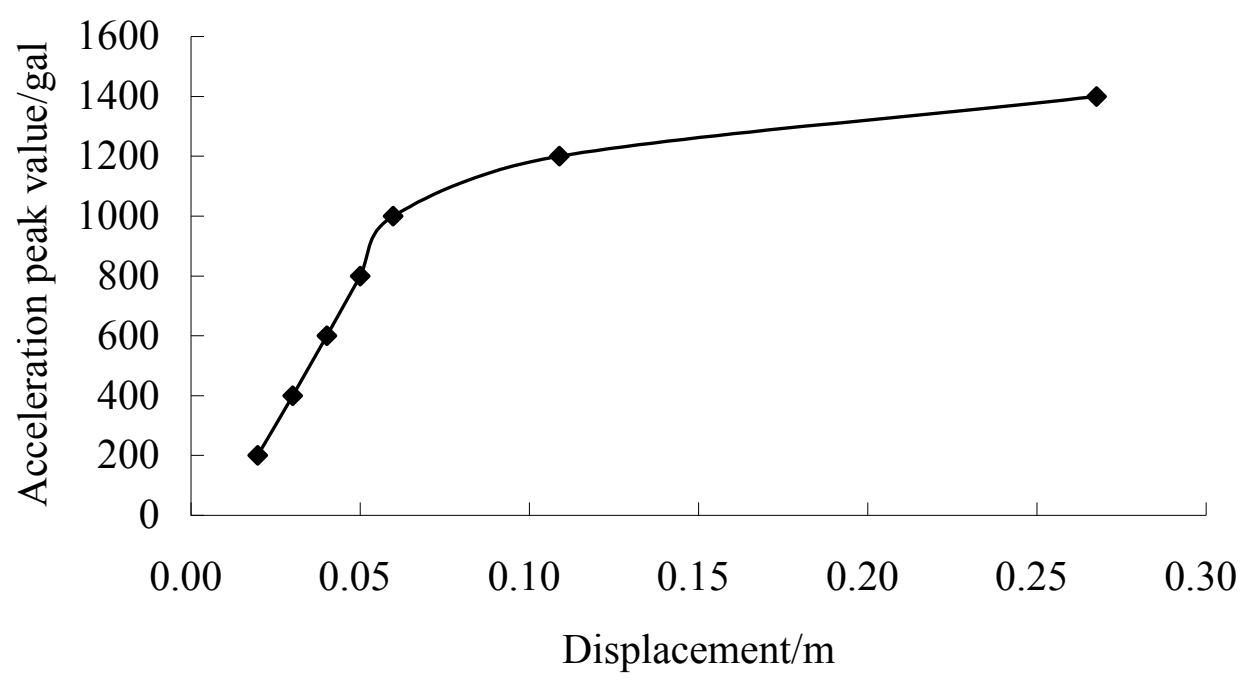

Figure 7. Maximum Vertical Displacements under Different Acceleration Peak Value

\section{INFLUENCES OF VARIOUS FACTORS}

When supports are both fixed hinged, the dynamic response of the structure under earthquake loads is mild. The orders of magnitude of the horizontal displacements are approximately $10^{-16} \mathrm{~m}$ or $10^{-15} \mathrm{~m}$. More attention is paid to the responses of vertical displacements in the following work.

\subsection{The Number of Struts}

Struts are elastic supports to the upper arch in the structure. The improvement of struts to the stabilization of the structure under earthquake loads is studied, and models composed of 1, 3, 5, 7 and 9 struts are adopted. Other calculated parameters of these five models are identical. From Figure 8 , according to the increase in the number of struts, midspan upper chord nodal vertical displacement increases initially, and after the number of struts reaches 5 , its value begins to drop. Thus, the proper number of struts needs to be studied and then adopted. In general, the order of magnitude of the displacement is $10^{-2} \mathrm{~m}$, so the influences of number of struts are not significant.

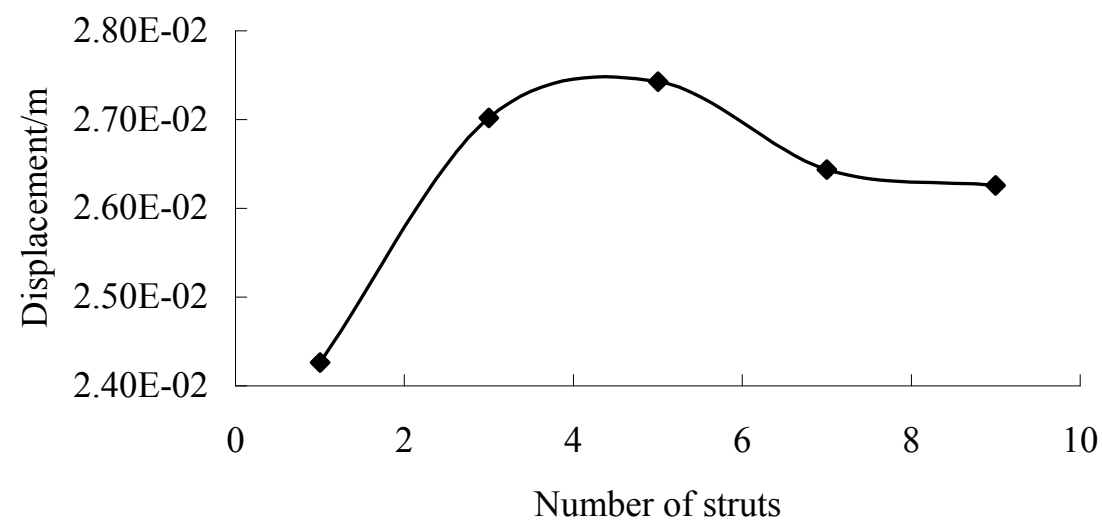

Figure 8. Maximum Vertical Displacements of Midspan Node under Different Numbers of Struts 


\subsection{The Ratio of High-span}

Six models with different high-span ratios are analyzed to study the effect of high-span ratio on load-carrying performance of BSS. Three struts are taken. Besides the different high-span ratios, other parameters are identical. As shown in Figure 9, midspan upper chord nodal vertical displacement declined considerably as the high-span ratio increased. In this case, it illustrates that the increase of high-span ratio is decisive to resisting integral deformation. Meanwhile, what should be noted is that the displacement dropped slightly when the high-span ratio is over 0.07 , compared with that of its ratio under 0.07 , which has a significant reduction. It elucidates that increasing high-span ratio can lessen the response of this structure under earthquake loads.

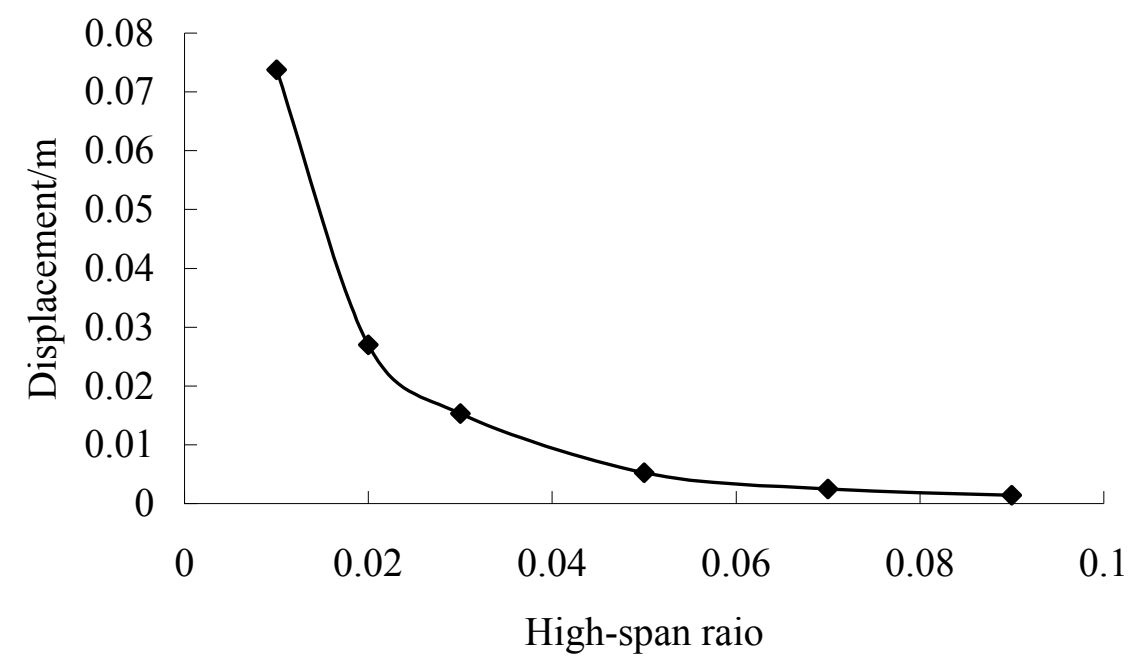

Figure 9. Maximum Vertical Displacements of Midspan Node under Different High-span Ratios

\subsection{The Ratio of Sag-span}

Eight models with different sag-span ratios are analyzed to study its effect on load-carrying performance of BSS. Three struts are also introduced. Besides the diverse sag-span ratios, other parameters are equal. Figure 10 describes that the value of midspan upper chord nodal vertical displacements rises moderately with the growth of sag-span ratio. It clarifies that lessening the sag-span ratio appropriately helps to reduce the vertical displacement response of this structure under earthquake load. In this case, the value of sag-span ratio should be kept in a rational extent.

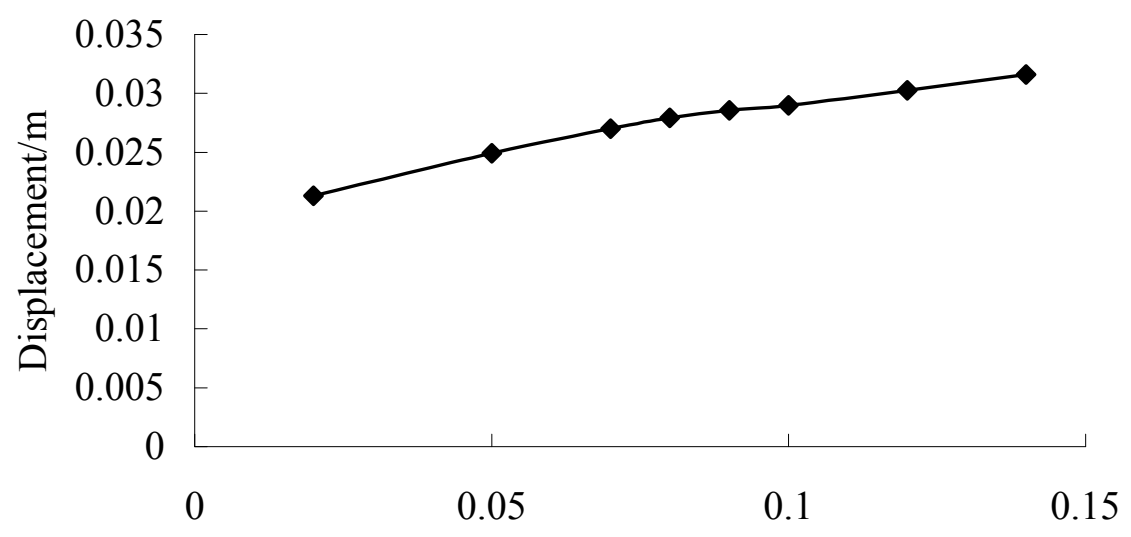

Sag-span ratio

Figure 10. Maximum Vertical Displacements of Midspan Node under Different Sag-span Ratios 


\subsection{Stiffness of the Upper Beam}

Three models with different section inertia moment are analyzed to study its impact on load-carrying performance of BSS. Besides the different sectional situation, other parameters are identical. From Figure 11, there is little change in deflection of the midspan upper chord nodal vertical displacement with the increase of sectional inertia moment. It reveals that the effect of sectional dimension on performance of this structure is little .

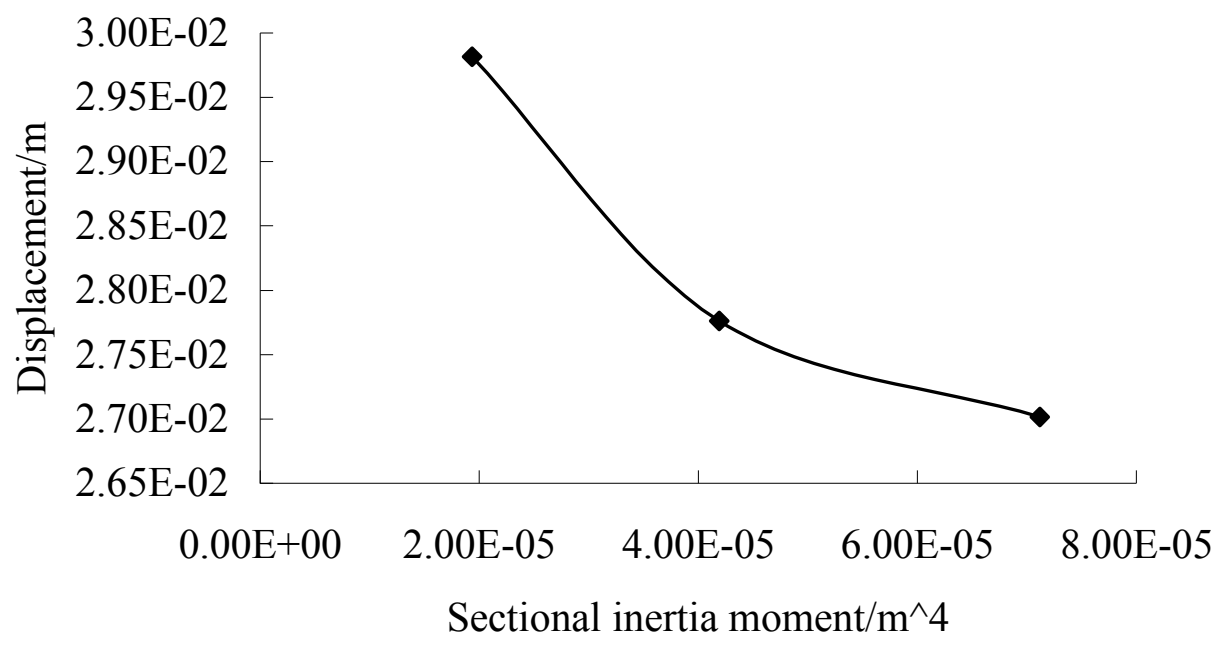

Figure 11. Maximum Vertical Displacements of Midspan Node under Different Sections

\subsection{Prestressing Force of Lower Cables}

Three models with different prestressing forces in the string are analyzed to study its effect on load-carrying performance of BSS. Besides the prestressing force value applied in the string, other parameters are identical. Figure 12 depicts that there is stable rise in the response of midspan upper chord nodal vertical displacements with the multiplication of prestressing force. It indicates that the increase of prestressing force of string will develop the structure's dynamic response. However, these effects are not significant. Thus, the value of prestressing force of string should be maintained in a reasonable range.

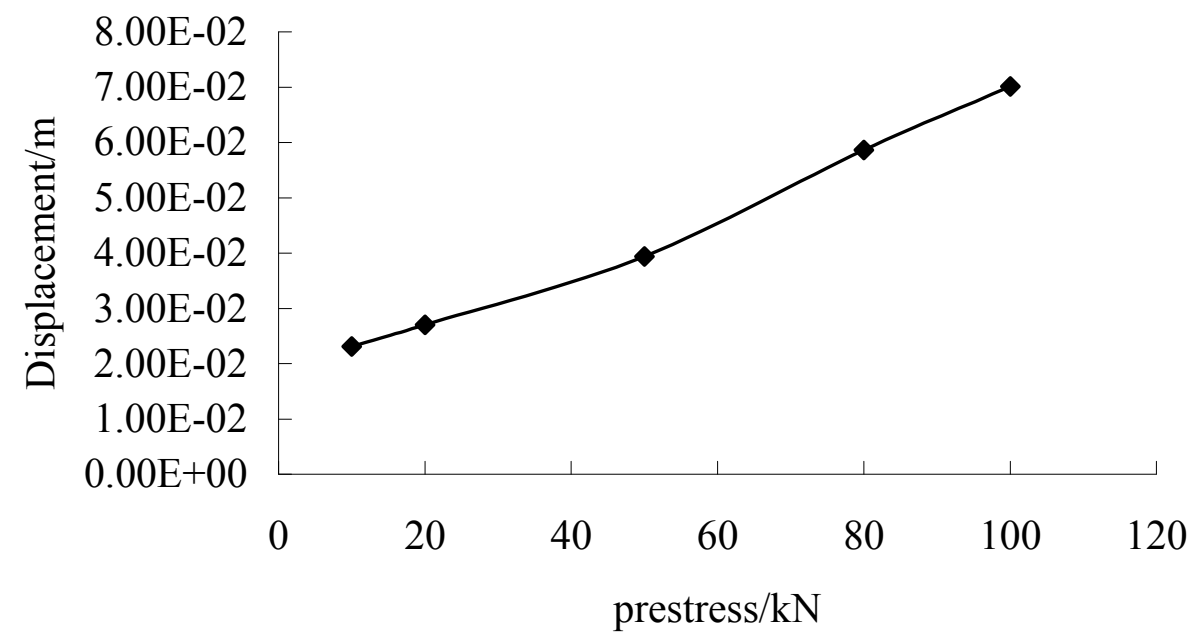

Figure 12. Maximum Vertical Displacements of Midspan Node under Different Prestressing Force of String 


\subsection{Restraint Type of the Supports}

On the premise of identical other parameters, when one end of the structure is fixed hinged support, while the other end is sliding hinged support, midspan upper chord node of the structure produces larger vertical displacement than that with two hinged supports do. As can be seen in Table 2, in the vertical displacement, the value of former has larger order of magnitude than that of the latter, in contrast, the gap is greater for horizontal displacement. It reveals that the effects of restraint type of the supports on performance of this structure are marked.

Table 2. Maximum Displacements of Midspan Node under Different Restraint Type of the Supports

\begin{tabular}{|c|c|c|}
\hline Restraint type & One fixed hinged support & Both fixed hinged support \\
\hline $\mathrm{UX} / \mathrm{m}$ & $1.05 \mathrm{E}-02$ & $7.57 \mathrm{E}-16$ \\
\hline $\mathrm{UY} / \mathrm{m}$ & $2.03 \mathrm{E}-01$ & $2.70 \mathrm{E}-02$ \\
\hline
\end{tabular}

\section{ELASTO-PLASTIC ANALYSIS}

The discussions above are limited to the elastic range. However, the plastic yielding will take place and be inevitable on the structure under earthquake loads. During the earthquake, when certain parts of the structure enters into plasticity, which gives rise to the re-distribution of internal force. Thus, the plastic nature of the structure and the material nonlinearity should be taken more cautiously.

When plastic yielding is taken into account, upper chords, lower cables and struts employ BEAM23, LINK10 and LINK1 elements respectively. Figure 13 shows the comparison of the maximum vertical displacements of the structure both in elastic and plastic ranges. Hereinto, Model A and Model $\mathrm{C}$ represent the dynamic responses of the structure in the elastic range, Model B and Model D stand for the dynamic responses of structure when elastic-plasticity occurs in the structure. Meanwhile, Model A and Model B are both of fixed hinged supports, and one ends support of Model C and Model D are of single fixed hinged while the other end support are sliding hinged. As clearly shown in Figure 13, the vertical displacement response of the structure (for Model A and B) rises just comparatively less moderately (when considering the influences of elastic-plastic property) than those of the structure (Model C and D) in the perfectly elastic range. It seems that the plasticity helps to improve the critical load of the dynamic stability.

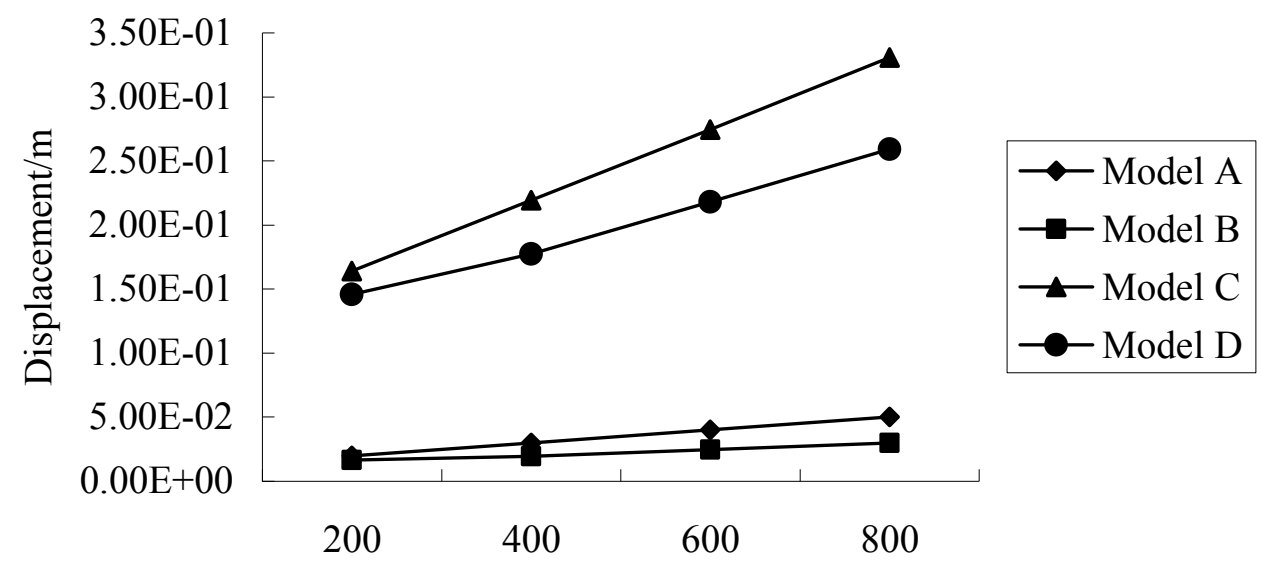

Acceleration peak value/gal

Figure 13. Maximum Vertical Displacement of Different Models 


\section{CONCLUSIONS}

Based on the discussion above, it can be concluded as follows.

1. Effect of various parameters on the dynamic response in $\mathrm{x}$ direction under vertical earthquake loads is not obvious.

2. Vertical displacement response of the structure changed indistinctively according to the variations in the number of struts. Only five numbers of struts are analyzed in this paper. The structures with more than 9 struts were not considered sufficient and should be further studied.

3. The increase of high-span ratio is conducive to the strengthening of structural stiffness and resisting integral deformation. Moreover, load-carrying performance of the structure under earthquake loads is improved. In contrast, the influences of sag-span ratio are more complicated. Therefore, the value of sag-span ratio should be kept in a rational extent.

4. Although increasing sectional dimension and inertia moment can enhance a certain degree of structural stiffness, the improvement on the dynamic performance of this structure is little.

5. There is larger deformation to inverted arch as the prestressing force increases, which can enhance a certain degree of structural stiffness and also can increase the initial dynamic response of the structure. In this case, the value of prestressing force of strings should be taken reasonably.

6. Compared with the static stability analysis, the effect of section situation on the structure is not obvious. Increasing the prestressing force of string will enhance the earthquake response. In addition, increasing sag-span ratio seems not to take such a positive role in the dynamic analysis. Results of the effects of other parameters on this Beam String Structure are consistent with the results of the static analysis.

7. Under comparatively weak seismic loads, the dynamic responses in the structure, taking the elastic-plastic property into consideration, is less than those in the elastic range. However, dynamic stability of elastic-plasticity should be further studied; more proper model should be strictly employed.

8. As discussed above, in terms of BSS with comparatively small span, the dynamic response is not strong. Small span has advantage to resist destabilization and to enhance the structural stability. When it comes to the longer span BSS, the stiffness of the structure will diminish rapidly, the potential probability of dynamic instability is increased. Furthermore, more and more larger span Beam String Structures are employed in the practical project, in this case, BSS with long span should be exactly researched for further development.

\section{ACKNOWLEDGEMENTS}

Funding for the project was provided by the National Natural Science Foundation of China (No.50608054) and the High Education Development Foundation of Tianjin (No.20031105). The support is gratefully acknowledged. The technical consultation provided by Professor Xingye Liu throughout the whole process is appreciated. 


\section{REFERENCES}

[1] Saitoh, M., "Role of String-aesthetics and Technology of the Beam String Structures", Proceeding of the LSA98 Conference-Light Structure in Architecture Engineering and Construction, 1998, pp. 692-701.

[2] Huang, M.X., "Design and Construction of Long-span Beam String Structures" (in Chinese), Shandong Science and Technology Publishing Company, 2005, pp. 1-9.

[3] Saitoh, M. and Okada, A., "The Role of String in Hybrid String Structure", Engineering Structures, 1999, Vol. 21, pp. 756-769.

[4] Zhang, Y.G. and Xue, S.D., "Long-span Space Structure" (in Chinese), Beijing Mechanical Industry Publishing Company, 2005, pp. 355-359.

[5] Chen, R.Y., Dong, S.L. and Sun, W.B., "Design and Analysis of a Long-span Prestressed Truss String Structure" (in Chinese), Spacial Structures, 2003, Vol. 9, No. 1, pp. 45-47.

[6] Shi, G.P., Chan, S.L. and Lu, Z.T., "Second-order Analysis and Design of Cables and Cable-frames", International Journal of Structural Stability and Dynamics, 2005, Vol. 5, No. 4, pp. 521-537.

[7] Bai, Z.X., Liu, X.L. and Li, Y.S., "Influence Analysis of Factors of Beam String Structure" (in Chinese), Steel Structures, 2001, Vol.3, No. 16, pp. 42-46.

[8] Bai, Z.X. and Liu, X.L., "Mechanics and Programming of Beam String Structure" (in Chinese), Engineering Mechanics Supplement, 1998, pp. 157-162.

[9] Liu, K.G., "Analysis of Large-span Beam String Structure” (in Chinese), Spacial Structures, 2001, Vol. 7, No. 2, pp. 39-43.

[10] Shu, Z.Z. and Zhang, J.Y., "Stability of Movement" (in Chinese), China Railway Publishing Company, 2001, pp. 12-13.

[11] Goldhirsch, I., Sulem, P.L. and Orszag, S.A., "Stability and Lyapunov Stability of Dynamical Systems-a Differential Approach and a Numerical Method", Physics, 1987, Vol. 27, pp. 311-337.

[12] Gilat, R. and Aboudi, J., "The Lyapunov Exponents as a Quantitative Criterion for the Dynamic Buckling of Composite Plates", International Journal of Solids and Structures, 2002, Vol. 39, pp. 461-481.

[13] Bernal, D., "Instability of Buildings During Seismic Response", Engineering Structures, 1998, Vol. 20, No. 4-6, pp. 496-502.

[14] Gui, G.Q. and Lin, Z.B., "Dynamic Stability of Single-layer Reticulated Spherical Domes" (in Chinese), Journal of Nanchang University (Engineering \& Technology), 2003, Vol. 25, No. 1, pp. 43-47.

[15] Guo, H.S., Qian, H.L. and Shen, S.Z., "Dynamic Stability of Single-layer Reticulated Domes under Earthquake Excitation" (in Chinese), Earthquake Engineering and Engineering Vibration, 2003, Vol. 23, No. 1, pp. 31-37.

[16] Guo, H.S. and Shen, S.Z., "Analysis Method of Dynamic Stability of Single-layer Reticulated Domes" (in Chinese), Journal of Building Structures, 2003, Vol. 24, No. 3, pp.1-9.

[17] Ye, J.H. and Shen, Z.Y., "Dynamic Stability of Single-layer Spherical Domes under Earthquake Action" (in Chinese), Engineering Mechanics Supplement, 1998, pp. 6-10.

[18] Xia, K.Q., Yao, W.X. and Dong, S.L., "Dynamic Behavior of Snap-through Buckling in Reticulated Domes" (in Chinese), Engineering Mechanics, 2002, Vol. 19, No. 1, pp. 9-13. 